\title{
Perinephric Abscess: a rare manifestation of extrahepatic amoebiasis
}

\author{
Sirikelum KGKP, KodikaraArachchi RW \\ Teaching Hospital, Karapitiya, Galle, Sri Lanka \\ Correspondence:Dr.K.G.K.P. Sirikelum (Siri.kelum@yahoo.com)
}

\section{Introduction}

Extra intestinal amoebiasis occurring in the perinephric region is extremely rare and often mistaken for a pyogenic perinephric abscess. Diagnosis is based on the identification of trophozoites of entamoeba histolytica in the aspirate and the disease is curable with standard anti-amoebal $\operatorname{drugs}(1)$.

\section{Case Report}

A 45-year old man was admitted with complaints of diffuse abdominal pain, loss of appetite and low grade fever for one week duration. His past medical history was unremarkable. On examination he was febrile and there was left renal angle tenderness. The rest of the clinical examination was unremarkable.
On investigation, his capillary blood sugar was $300 \mathrm{mg} / \mathrm{dL}$, total white cell count was elevated with neutrophil predominance and ESR was $90 \mathrm{~mm}$. Ultra sound scan of the abdomen and pelvis showed mixed echogenic lesion in the lower pole of the left kidney $[7.9 \mathrm{~cm} \times 4.1 \mathrm{~cm}]$ suggestive of a left perinephric abscess. Contrast CT abdomen showed a left perinephric abscess in relation to the lower pole of the kidney (Figure 1). A nephrostomy tube was inserted and anchovy-sauce-like fluid $250 \mathrm{cc}$ was removed (Figure 2). Direct smear of the fluid showed Entamoeba histolytica trophozoites (Figure 3). Treatment with intravenous metronidazole was commenced. The drainage continued for two weeks. Repeat ultra sound scan after two weeks of nephrostomy showed no remnants of perinephric abscess, seen previously. 


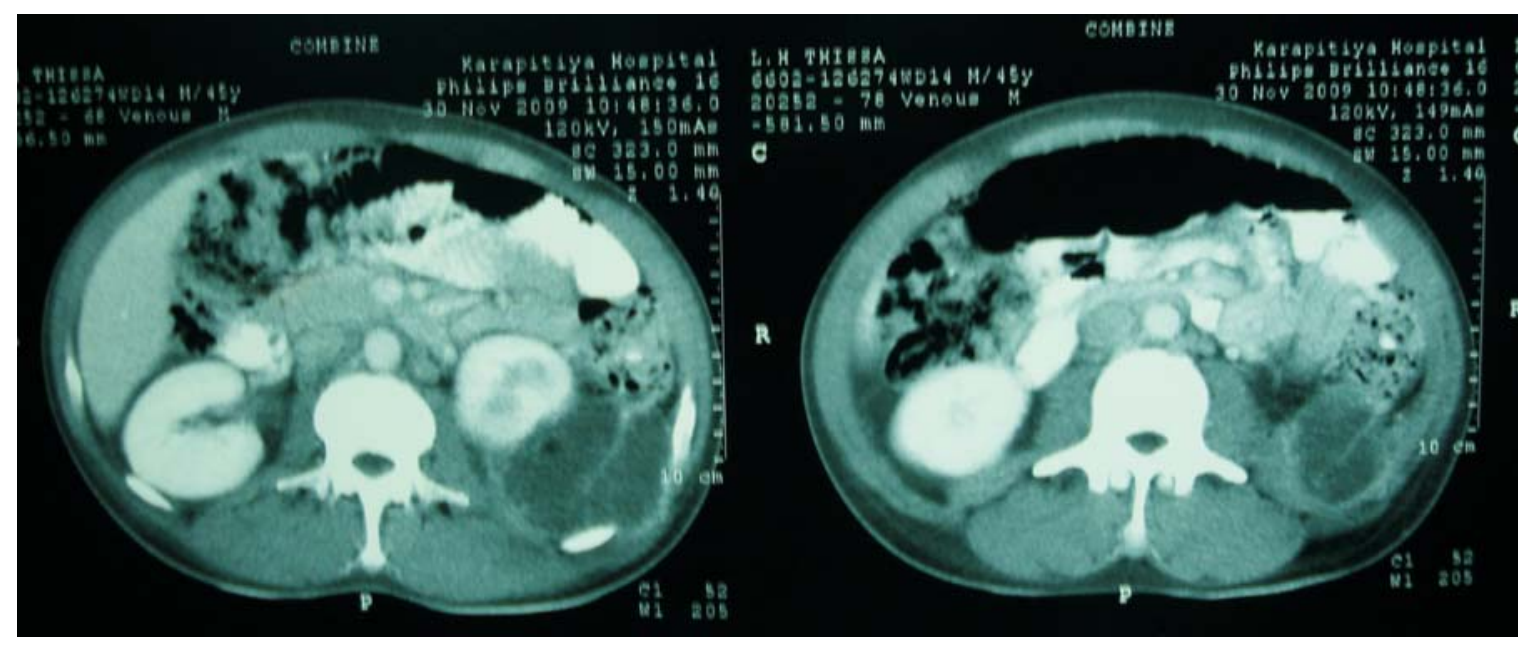

Figure 1: CT abdomen showing left perinephric abscess

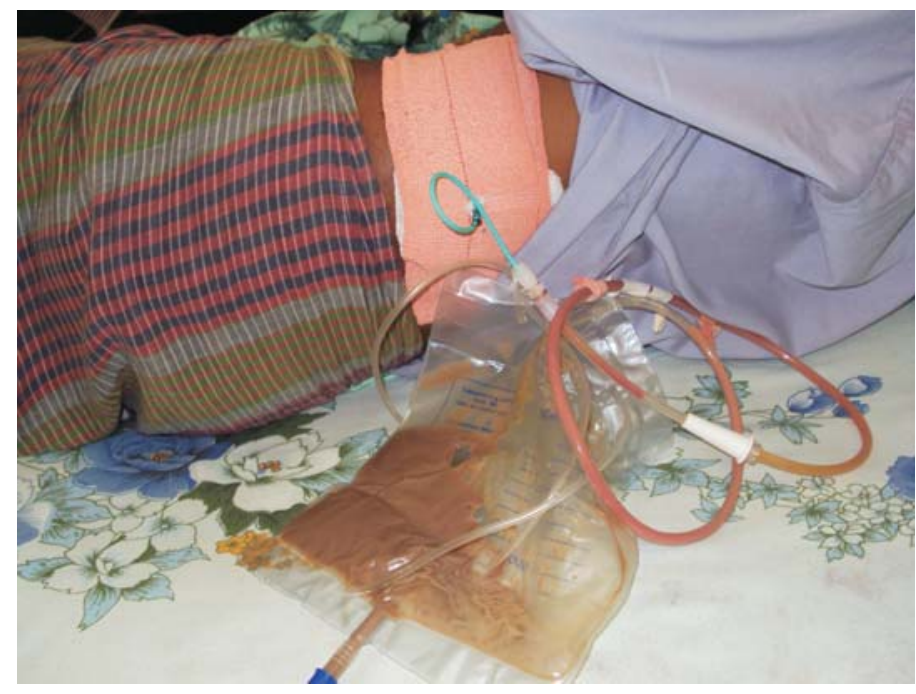

Figure 2: Anchovy-sauce-like fluid (necrotic contents of the amoebic perinephric abscess)
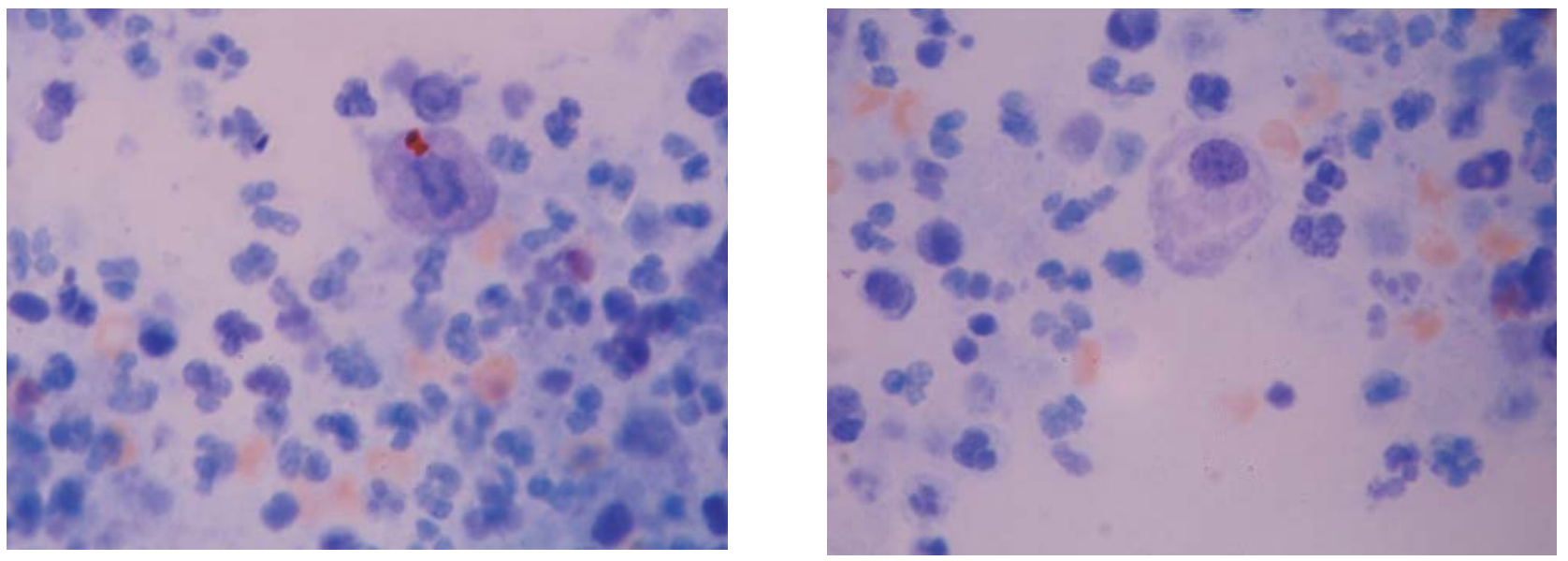

Figure 3: Trophozoites of $E$. histolytica under light microscope 


\section{Discussion}

Among extra intestinal complications which may occur in patients with or without symptoms of amoebic dysentery are amoebic hepatitis, hepatic abscess, lung abscess, amoebic bronchitis, amoebic pleurisy, cerebral abscess, splenic abscess, cutaneous amoebiasis, amoebic pericarditis, amoebiasis of vagina, uterus, ovary, fallopian tubes, testicles, epididymis and penis. Amoebic infestation of the gallbladder and biliary system has been reported and subdiaphragmatic collection due to Entamoeba histolytica is not a rarity (2).

Urinary complications of amoebiasis are cystitis, pyelitis, nephritis, urethritis and kidney abscess. Perinephric abscess is an extremely rare manifestation of Entamoeba histolytica infection. Entamoeba histolytica is acquired by ingestion of viable cysts from fecally contaminated water, food, or hands. Less common means of transmission include oral and anal sexual practices and direct rectal inoculation through colonic irrigation devices. Motile trophozoites are released from cysts in small intestine and in some patients remain as harmless commensals in the large bowel. In some patients trophozoites invades the blood stream causing distance abscesses in kidney and perinephric region $(3,4)$.

Both trophozoites and cysts are found in the intestinal lumen, but only trophozoites of Entamoeba histolytica invade tissue. Trophozoites attach to colonic mucus and epithelial cells by Gal / Gal Nac receptors. Cytolytic effect of amoebiasis appears to require direct contact with target cells and may be linked to the release of phospholipase A and pore-forming peptides.Entamoeba histolytica trophozoites also cause apoptosis of human cells. Blood vessels may be invaded early by wall lysis and thrombus formation. Entamoeba histolytica resistant to compliment mediated lysis, persist in the blood (5).

Perinephric abscess can be from direct extension of amoebiasis from the colon or by haematogenous spread of the infection(4).

\section{Conclusion}

Perinephric amoebic abscess is an extremely rare manifestation of extra intestinal amoebiasis but it should be kept in mind particularly in tropical countries.

\section{References}

1. R. Knight. Amoebiasis. In: David A. Warrell, T.M. Cox, John D. Firth. Oxford Textbook of Medicine, $4^{\text {th }}$ edition, Volume 1, Oxford University Press, New York, 2003: 714-720.

2. Major John A. Ross. Amoebic perinephric abscess. British Journal of Radiology, 1944; 17: 289-290.

3. Sharon L. Reed. Amoebiasis and infection with free living Amoebas. In: Harrison's Principles of Internal Medicine, $17^{\text {th }}$ edition, volume 1 :

4. M.J.G, Farthing, A.M. Cevallos and P.Kelly. Intestinal Protozoa. Manson's Tropical Diseases, $21^{\text {st }}$ edition, Section - 10. Chapter 77.

5. Kirsh David, Diaz-Rivera RS. Perinephric Abscess-A Previously Unreported Complication of Amebiasis. The American Journal of Medical Sciences. September 1943; 206(3): 372-378. 